\title{
The Dual Identity of the Post-Verbal Can1 in Cantonese: A Non-Specific Resultative Particle and a Free Choice Item
}

\author{
Joanna Ut-Seong Sio \\ Palacký University Olomouc
}

\begin{abstract}
This paper discusses the syntactic and semantic properties of the two functions of the post-verbal canl in Cantonese. The first function of the post-verbal canl is a non-specific resultative particle that denotes any degree on a "bodily harm" scale. The non-specific nature of canl ensures that the scale is always a simplex scale (containing only a beginning and an end) and thus [V-canl] predicates behave like achievement verbs. The second function of the post-verbal canl is a free choice item (FCI). It appears only in non-episodic sentences, specifically in doul (iota operator)-conditionals or zau6 (necessity operator)-conditionals.
\end{abstract}

\section{Keywords}

Cantonese, resultative particle, scale, free choice item

Studies in Chinese Linguistics, Volume 41, Number 2, 2020, 139-160 DOI: 10.2478/scl-2020-0005 (C) 2020 Joanna Ut-Seong Sio. Studies in Chinese Linguistics is published by Sciendo on behalf of T.T. Ng Chinese Language Research Centre, Institute of Chinese Studies, The Chinese University of Hong Kong. This work is licensed under the Creative Commons Attribution-NonCommercial-NoDerivatives 4.0 International License. 


\section{Introduction}

Cantonese has a rich inventory of post-verbal particles. They are placed right after the verb and before the object, when present:

\section{(1) subject V-particle(s) (object)}

These particles serve innumerable grammatical functions, such as aspect, direction, result, quantification, etc. (Matthews and Yip 2011). This paper focuses on the particle canl, which has two very distinct functions. Matthews and Yip (2011) call the two functions "adversative" and "habitual" (see also Cheung 2007; Tang 2015). We continue to use these terms to refer to the two functions of canl throughout the paper as descriptive terms. The adversative function of canl is shown in (2a) and (2b):
a. Pit1taa4
zong6-can1
zek3 maau1 aa3.
Peter bump.into-CAN
$\mathrm{CL} \quad$ cat $\mathrm{SFP}^{2}$
'Peter bumped into the cat and as a result the cat was hurt.'
b. Pit1taa4 haak3-can1 go3 bi4bi1 aa3.
Peter scare-CAN CL baby SFP
'Peter scared the baby and as a result the baby was negatively affected (psychologically).'

The adversative can 1 encodes a negative result related to bodily harm. It could be physical or psychological. In (2a), canl provides the additional meaning that the cat was physically hurt as a result of the bumping event. In (2b), haak3 'scare' is a psychological verb and the negative result is interpreted as psychological (e.g., the baby cried or became more irritable). The nature and degree of the negative effect depend on the lexical meaning of the verb and the context.

The second function of canl is very different. Matthews and Yip (2011) describe it as "habitual":

$\begin{array}{lllll}\text { Pit1taa4 } & \text { coeng3-can1 go1 dou1 hau4lung4-tung3 gaa3. } \\ \text { Peter } & \text { sing-CAN } & \text { song all throat-sore } & \text { SFP } \\ \text { 'Peter } & \text { has sore throat whenever he }{ }_{\mathrm{i}} \text { sings.' }\end{array}$

1 Canl is written as 親 orthographically, which has the general meaning of 'kin' or 'intimacy'. The two functions of the Cantonese post-verbal particle canl do not seem to be related to this meaning. There are several possibilities. It can be that canl is highly grammaticalized (Gu and Yip 2004) and has lost its original meaning. It could also be that the character 親 and the post-verbal canl are unrelated. Cantonese is primarily a spoken Chinese variant and has never been subjected to rigorous and formal standardization (Li 2000). The character 親 could have been used solely based on phonological identity. There are a lot of colloquial vocabulary items in Cantonese which are not found in other dialectal groups (Yue-Hashimoto 1991). There is no equivalent of the post-verbal canl in Mandarin, for instance. The post-verbal canl could also be a borrowing from other languages which had been in contact with Cantonese historically, such as Miao or Tai. I leave this issue open.

$2 \mathrm{SFP}=$ Sentence-final-particle 
The habitual canl generally occurs in subordinate clauses (e.g., protasis of conditionals) and expresses a universal quantification meaning of 'whenever' (Lee 2017).

This paper discusses the syntactic and semantic properties of the two functions of can1, though the focus of discussion would be mainly on the adversative can1. Agreeing with $\mathrm{Gu}$ and Yip (2004), I treat the adversative canl as a "special" resultative particle. It is special because it does not encode a specific result state, yet it has a bounded interpretation. Based on Sio (2015), I adopt the Affectedness Hierarchy (Beavers 2011) in explaining the semantic restrictions on $\mathrm{V}$ in [V-canl] predicates: only dynamic verbs that encode non-quantized and potential change in the Affectedness Hierarchy are compatible with the adversative can1. Furthermore, $\mathrm{V}$ in [V-can 1] must relate to bodily harm, either physical or psychological. Hence, the affected argument must be [+animate] (including body-parts). I argue that adversative [V-can1] predicates contain a property scale similar to other change-ofstate predicates (Hay et al. 1999). The property scale for canl is "bodily harm", with the degrees ranging from "discomfort" to "severely injured". The adversative can 1 does not specify a specific result, yet [V-can 1] predicates behave like achievements. I argue that precisely because any degree of harm can be the endpoint/result state, the property scale associated with canl is always a simplex scale containing only the starting point and the end point (without any middle portion). This accounts for why adversative [V-can1] predicates are achievements aspectually. Syntactically, I adopt a structure where there are three aspectual projections between VP and $v \mathrm{P}$ in Chinese (Sybesma 2017; Lu et al. 2019): Asp1P (hosting resultative particles, associated with telicity), Asp2P (hosting phase complements), and Asp3P (hosting aspectual particles associated with realization). In view of the lack of lexical content and the obligatory achievement interpretation of [V-canl] predicates (which are similar to phase complements), I treat can 1 as Asp $2^{0}$ and the affected argument is in SpecAsp2. The habitual can1 generally does not pose any selectional restriction on the verb it combines with, but it cannot appear in episodic sentences. I treat the habitual canl as a free choice item (FCI). It must appear in environments containing a Q(uantificational)-operator and can either be definite or indefinite (Giannakidou and Cheng 2006; Cheng and Giannakidou 2013). The definite FCI can1 has to appear in the presence of doul, which I treat as an iota/maximality operator, following Cheng (2008). The indefinite FCI canl appears in conditionals with a necessity operator.

\section{Adversative can1}

$\mathrm{Gu}$ and Yip (2004) analyze the adversative canl as a resultative particle that encodes a negative result. It is in complementary distribution with other resultative particles (e.g., sei2 'die'). (4) is ungrammatical regardless of the ordering of the two resultative particles, canl and seil 'die' as only one resultative particle can be present. They also note that canl cannot be further specified by another resultative element in the same sentence as shown in (5) (taken from Gu and Yip 2004, their 
example [30b]). Can1 can co-occur with aspectual particles. (6) shows the cooccurrence of canl with the experiential aspectual particle gwo3.

$$
\begin{array}{llll}
* \mathrm{Ngo5} & \text { zong6-can1-sei2 } & \text { zek3 maau1. } \\
\text { 1SG } & \text { bump.into-CAN-die } & \text { CL } & \text { cat }
\end{array}
$$

(5) Go3 bi4bi1 haak3-can1 (*jat1 tiu3). CL baby scare-CAN one jump 'The baby got scared.'

(6) Pit1taa4 zong6-can1-gwo3 zek3 maau1.

Peter bump.into-CAN-EXP ${ }^{3}$ CL cat

'Peter have bumped into the cat and as a result hurt the cat before.'

Unlike other resultative particles (e.g., sei2 'die' or laan6 'broken', etc.), the adversative canl cannot be used as an adjective as it lacks lexical meaning and it does not denote a specific result state (Gu and Yip 2004).

\subsection{Animacy}

Adversative [V-canl] predicates require an affected argument. Since only sentient beings are able to experience adversity, adversative [V-canl] predicates require the affected argument to be [+animate] (Gu and Yip 2004). This means the subject has to be [+animate] in intransitive cases, (7). The only exception is body-part subjects as shown in (8b):

(7) Ngo5 zong6-can1.

$1 \mathrm{SG}$ bump.into-CAN

'I bumped into something and got hurt.'

(8) a. \#Bou6 ce1 zong6-can1.

CL car bump.into-CAN

'The car was hurt as a result of bumping into something.'

b. Ngo5 zek3 goek3 zong6-can1.

1SG CL foot bump.into-CAN

'My foot was hurt as a result of some bumping event.'

Only animate entities can enter a possessive relation with a body-part. When a body-part is attached to an animate object, it can feel pain. I assume it is this animacy connection that allows body-parts to function as the affected argument for [V-canl] predicates.

There are more variations in transitive cases. When the object is [+animate], the affected argument is the object (Cheung 2007: 166). In such cases, the subject can be an agent, an instrument, or a causer. (2a) is repeated here as (9):

3 Experiential aspect 
Agent subject:

(9)
Pit1 taa4 zong6-can1
zek3 maau1 aa3.
Peter bump.into-CAN CL cat SFP
'Peter bumped into the cat and as a result the cat was hurt.'

Instrument subject:

(10)
Bou6 ce1 zong6-can1
zek3 maau1 aa3.
$\mathrm{CL}$ car bump.into-CAN CL cat SFP

'The car bumped into the cat and as a result the cat was hurt.'

Causer subject:

(11) Sim2din6 siu1-can1 zek3 maau1 aa3.

lightning burn-CAN CL cat SFP

'The lightning burned the cat to a certain degree.'

Cases where the subject is [+animate] and the object is not are also reported in the literature. An example from Cheung (2007: 166) is shown below:

(12) \#Keoi5 tek3-can1 gau6 sek6.

3SG kick-CAN CL stone

'S/he kicked the stone and as a result s/he was hurt.'

Cheung (2007) argues that the affected argument is the subject in such cases as it is the only [+animate] argument. It should be noted that some informants find examples like (12), where the object is inanimate, marginal. They get the surreal interpretation that the stone is personified and hurt. Tang (2015) also indicates that such examples are marginal. He observes that if the object in (12) contains a demonstrative, e.g., neil 'this' (i.e., neil gau6 sek6 'this stone'), the surreal personified reading of the stone becomes much stronger.

Transitive cases with inanimate objects only sound natural if the object is a body-part:

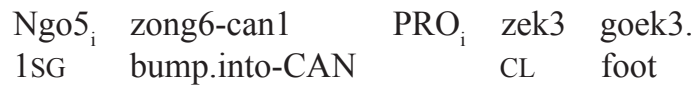

'I bumped into something and hurt my foot.'

(14) Ngo5 zong6-can1 keoi5 zek3 goek3.

1SG bump.into-CAN 3SG CL foot

'I bumped into and hurt her/his foot.'

It can be seen in (13) that the possessor of the object possessive phrase is bound by the subject, but it does not have to be, as shown in (14). Again, body-parts (that are connected to a living thing) are considered [+animate] and can act as the affected argument. 
To recap, [V-can1] predicates exhibit the following patterns, with the affected argument underlined:

(15) a. subject [+animate (including body-parts)] V-can1

b. \#subject [-animate] V-can1

c. subject [+/-animate] V-canl object [+animate (including body-parts)]

d. \#subject [+animate] V-can1 object [-animate]

\subsection{Restrictions on $\mathrm{V}$ in [V-canl] predicates}

Can1 poses semantic restrictions on the verb it combines with. ${ }^{4}$ Beavers (2011) identifies 4 classes of dynamic verbs that encode different degrees of affectedness on the event participant $\mathrm{x}$ in descending order. This is illustrated below:

(16) The Affectedness Hierarchy (Beavers 2011)

a. $\mathrm{x}$ undergoes a quantized change (e.g. peel, kill, shatter $\mathrm{x}$ ).

b. $\mathrm{x}$ undergoes a non-quantized change (e.g. flatten, cut, widen $\mathrm{x}$ ).

c. $\mathrm{x}$ has potential for change (e.g. hit, wipe, rub $\mathrm{x}$ ).

d. $\mathrm{x}$ is unspecified for change (e.g. see, smell, ponder $\mathrm{x}$ )

For type (a) verbs, the participant reaches a precise result state. The result is encoded as part of the semantics of the verb (e.g., kill, being killed means the victim results in death). In type (b) verbs, the result on the participant is entailed, but it is not uniquely specified (e.g., flatten, a piece of dough can be flattened to different degrees). In type (c) verbs, a change on the participant is possible, but there might not be one (e.g., hit, being hit by a baby may not result in any observable change). In type (d) verbs, there is no change (e.g., see, being seen would not cause any change).

Sio (2015) observes that the Affectedness Hierarchy captures the semantic restrictions on $\mathrm{V}$ in adversative $[\mathrm{V}$-can 1$]$ predicates. The adversative canl is compatible only with dynamic verbs indicating a non-quantized change, (b) and potential for change, (c). Some Cantonese examples illustrating the 4 classes are given below:

(17) a. quantized change, e.g., saat3 'kill': *saat3-can1

b. non-quantized change, e.g., gat1 'prick': gat1-can1

c. potential for change, e.g., daa2 'hit': daa2-can1

d. unspecified for change, e.g., paau2 'run': *paau2-can1

4 Phonologically, Gu and Yip (2004) observe that the adversity canl only combines with monosyllabic verbs. One reviewer, however, provided us with this disyllabic example:

(i) joeng2seoil-can1 nei5 ugly-CAN1 2SG

Joeng2seoil is a colloquial derogatory term and the sentence has the meaning of someone/ something being too ugly and the ugliness affects you negatively. Our informants, however, find this example marginal. Note that joeng2seoil is not a dynamic verb. 
Canl is incompatible with verbs that encode quantized change because a result state is already incorporated into the lexical semantics of such verbs. There cannot be another result. This can be ruled out by the "further specification constraint", proposed by Tortora (1998). It states that a verb that is inherently delimited may occur with a resultative only if the resultative acts as an additional specification of the result already inherent in the verb's meaning. In cases like saat3 'kill', the lexically encoded end-state cannot be further specified as canl does not provide any further specification and moreover its non-specific value is in contradiction with the precise end-state ("dead") encoded by saat3 'kill'. Canl is also not compatible with verbs that are not specified for change. This suggests that canl cannot induce a change-of-state interpretation if the lexical semantics of the verb does not already specify a non-quantized change or a potential change. This makes canl different from other resultative particles, e.g., soengl 'injured', which have clear lexical meanings and can combine with verbs that are unspecified for change. The contrast is illustrated with the verb paau2 'run':

(18) a. *paau2 'run'-can1

b. paau2 'run'-soengl 'injured'

Soeng1 'injured' can induce a change-of-state interpretation when added to paau2 'run' (unspecified for change) while canl cannot.

The difference between verbs encoding non-quantized change (e.g., caap3 'stab') and verbs encoding potential change (e.g., zong6 'bump into') are shown in the following examples:

Caap3 'stab' (non-quantized change):
a. X caap3-dou2 Y
b. X caap3-can1 $\mathrm{Y}$

Zong6 'bump into' (potential change):

a. X zong6-dou2 $\mathrm{Y}$
b. X zong6-can $1 \mathrm{Y}$

Dou2 is a post-verbal particle. It belongs to the category of "phase complements" (Chao 1968: 446). Literally, it has the meaning of 'arrived', but its meaning is more abstract here. ${ }^{5}$ When combined with $\mathrm{V}$, it means the action denoted by the preceding V has been successfully accomplished. In (19), caap3 'stab' encodes a non-quantized change and it presupposes a puncture on the skin though the wound can be of different degrees of severity. In this case, (19a) entails (19b). In (20), zong6 'bump into' encodes a potential change, the bumping might not cause any impingement on Y, thus, (20a) does not entail (20b).

5 When used as a main verb meaning 'arrived' in Cantonese, it is dou 3 (mid-flat tone). As a phase complement, it is dou2 (high-rising tone). 
Not all verbs encoding non-quantized change and potential change are compatible with can 1 either since degree of affectedness is not the only semantic restriction. For example, jau4 'paint' encodes a non-quantized change but is incompatible with can 1:

$\begin{array}{llll}* \text { Ngo5 } & \text { jau4-can1 } & \text { keoi5 } & \text { aa3 } \\ 1 \mathrm{SG} & \text { paint-CAN } & 3 \mathrm{SG} & \text { SFP }\end{array}$

(21) is ungrammatical because the action jau4 'paint' does not involve physical or psychological harm. Even though jau4 'paint' entails a non-quantized change in the object (e.g., to different degrees of coloration), the change/effect is not of the right kind.

Gu and Yip (2004) list the following verb categories as compatible with the adversative canl:

(22) a. Physical actions involving specific body parts (e.g., bokl 'to get hit in the head', caai2 'to be tread on', etc.)

b. Psychological predicates (e.g., gikl 'to irritate')

c. Weather predicates (e.g., laang5 'to catch a cold')

It should be noted that canl is compatible also with verbs denoting physical actions that do not involve specific body parts being affected, but the body in general. For instance, zong6 'bump into', gwaat3 'abrade', gip6 'nip' and laat6 'scald' are all compatible with canl and they can affect any body-part. ${ }^{6}$

Combining the observations in Sio (2015) and Gu and Yip (2004), the semantic restrictions on $\mathrm{V}$ in [V-canl] predicates can be stated as follows:

(23) A dynamic verb is compatible with the adversative canl if and only if (i) it encodes a non-quantized change or a potential change and (ii) the result of the action can lead to bodily harm, either physical or psychological.

\subsection{Scale}

There are three types of incremental themes (Tenny 1994):

(24) a. Creation/Consumption predicates: John ate the fish.

b. Motion predicates: John walked to the store.

c. Change of state predicates: John scrubbed the sink clean.

Each of the examples above encodes a three-way relation between an event, a theme, and a scale. The type of scales differs depending on the verb type (Hay et al. 1999). For creation and consumption predicates, the scale is the spatial content of the theme argument (ascending for creation or descending for consumption). For motion predicates, the scale is the path of motion of the theme argument (a path from the original location of the theme to the final location of

6 The examples gwaat3 'abrade', gip6 'nip', laat6 'scald' were taken from Gu and Yip (2004) though they classify them as physical actions involving specific body-parts. 
the theme). The gradable property (of the resulted state) of the theme argument is the scale for change-of-state predicates. An example of the three-way relation with the change-of-state predicate scrub is shown in (25a) and its corresponding semantic representation in (25b):

(25) a. John scrubbed the bathtub clean.

b. $\exists \mathrm{e} \exists$ s [scrubbing' $(\mathrm{j}, \mathrm{b}, \mathrm{s}, \mathrm{e}) \wedge$ result' (s, clean, e)] (s is a cleanliness scale of the bathtub)

Resultative particles provide an endpoint along a property scale. For example, the resultative particle sei2 'dead' has "dead" as the endpoint:
a. Kristoff caap3-sei2-zo2 Olaf aa3. Kristoff stab-dead-PERF Olaf SFP 'Kristoff stabbed Olaf to death.'
b. $\exists \mathrm{e} \exists \mathrm{s}\left[\mathrm{stab}^{\prime}(\mathrm{k}, \mathrm{o}, \mathrm{s}, \mathrm{e}) \wedge\right.$ result' $\left.(\mathrm{s}, \underline{\text { dead }}, \mathrm{e})\right]$

Can1, being also a resultative particle, can also be modelled with a property scale. (27a) can be represented by (27b):

$\begin{array}{llll}\text { a. Kristoff } & \text { caap3-can1 } & \text { Olaf } & \text { aa3. } \\ \text { Kristoff } & \text { stab-CAN } & \text { Olaf } & \text { SFP }\end{array}$ 'Kristoff stabbed Olaf and as a result Olaf was hurt.'

b. $\exists \mathrm{e} \exists \mathrm{s}\left[\mathrm{stab}^{\prime}(\mathrm{k}, \mathrm{o}, \mathrm{s}, \mathrm{e}) \wedge\right.$ result' $\left.(\mathrm{s}, \mathrm{can} 1, \mathrm{e})\right]$

I propose that the property of the scale associated with all [V-canl] predicates is "bodily harm".

A scale constitutes an ordered set of degrees on a particular attribute (e.g., length, height, temperature). The degrees indicate the possible values of this attribute (Kennedy 2001). In [V-can1] predicates, can1 does not encode a specific degree of bodily harm. The nature of harm and the severity of the harm are codetermined by the verb and the context. Consider the following:
a. caap3 'stab'-can1
b. gat1 'prick'-can1

The degree of severity is perceived as higher in (28a) due to the nature of the verb. Both verbs involve puncturing the skin, but caap3 'stab' is understood as the action is done with a knife or some similarly sharp weapon whereas gat1 'prick' is understood as the action is done with less dangerous items like a needle.

The minimal degree of "bodily harm" can be one that is causing little discomfort:

$\begin{array}{llllll}\text { Go3 } & \text { dang1daam2 } & \text { caang4-can1 } & \text { ngo5 } & \text { deoi3 } & \text { ngaan5. } \\ \text { CL } & \text { light bulb } & \text { shine-CAN } & \text { 1SG } & \mathrm{CL}_{\text {pair }} & \text { eye }\end{array}$

'The light bulb shone on my eyes and as a result they now feel uncomfortable.'

7 I would like to thank one reviewer for pointing me to this kind of examples. 
Sio (2015) suggests that canl carries the meaning of "a small degree". She states that when canl is used, the injury is often interpreted not severe. I agree that canl is used in expressing non-serious injury in a lot of cases. One reviewer also mentioned that can1 goes with siu2siu2 'a little bit' and dit1dit1 'a tiny bit' quite naturally as shown in the following example:

$\begin{array}{lll}\text { Pit1taa4 zong6-can1 siu2siu2/dit1dit1 } & \text { ze1. }{ }^{8} \\ \text { Peter bump.into-CAN a little bit/ a tiny bit } & \text { SFP } \\ \text { 'Peter hit himself and hurt himself a little bit. } & \end{array}$

I do not agree, however, that the small degree reading is built into the semantics of canl, as it is also compatible with a "severely injured" reading:
A: Pit1taa4 bei2-ce1 zong6-can1 aa3.
Peter
PASS-car hit-CAN
SFP
'Peter was hit by a car and was hurt.'
B: Zong6 seng4 $\operatorname{dim} 2$ aa3?
hit to.the.extent how SFP
'To what extent was he hurt?'
A: Zong6-dak1
hou2 soeng1 aa3.
bump.into-to.the.extent very injured SFP
'[He] was hit to the extent that he was badly injured.'

(31) not only shows that canl does not specify the extent of harm, thus questions for further specification can be asked; it also shows that the "small degree" reading, if present, is only a preference and can be overridden. The reason for this "small degree" preference can be due to the existence of the resultative particle seongl "injured". It covers the range of injuries that would require medical attention and thus, there can be a lexical blocking effect. The more severe kind of injuries is covered by soengl even though canl is also semantically compatible with that.

To recapitulate, the "bodily harm" scale ranges from the minimal degree of discomfort to the maximal degree of severe injury. ${ }^{9}$ Canl can be any value on the "bodily harm" scale, and I believe that this "any value" property is related to why [V-can1] predicates are obligatorily achievements, as will be discussed in the next subsection.

\subsection{Aspectual properties of [V-canl]}

$\mathrm{Gu}$ and Yip (2004) observe that [V-canl] predicates behave like achievements. The resultative particle canl marks the event as telic and [ $\mathrm{V}$-canl] predicates are

8 Gu and Yip (2004) observe that canl cannot be further specified by another resultative element in the same sentence (their example is illustrated in the ungrammatical example [5]) and yet (30) is grammatical. I think (5) and (30) differ in that in (5), the further specified result jat1 tiu3 'one jump' is predicated of the affected argument (i.e., the baby), while in (30) the further specification is on the degree of the bodily harm.

9 The maximal degree cannot be "dead". 
not compatible with the progressive aspect. The following example is taken from Gu and Yip (2004: 46, their example [24]):

*Keoi5 hai2dou6 haak3-can1 go3 bi4bi1 wo3. ${ }^{10}$
3SG right.now scare-CAN CL baby SFP
Intended reading: 'S/He is making the baby scared.'

Hai2dou6 is a progressive aspectual adverb in Cantonese. It expresses that some process/activity is in progress (Matthews and Yip 2011). [V-can1] predicates are also incompatible with the progressive aspectual post-verbal particle gan2, as illustrated below:
*Keoi5 daa2-can1-gan2 zek3 gwaai3sau3 aa3 3SG hit-CAN-PROG CL monster SFP
Intended reading: ' $\mathrm{S} / \mathrm{He}$ is hitting the monster to achieve the result of hurting it.'

(33) will be grammatical without the progressive aspectual particle. If canl is replaced by another resultative particle, e.g., sei2 'dead', the progressive will be possible again:

$$
\begin{aligned}
& \text { Keoi5 (hai2dou6) daa2-sei2-gan2 zek3 gwaai3sau3 aa3. } \\
& \text { 3SG right.now hit-dead-PROG CL monster SFP } \\
& \text { 'S/He is hitting the monster to death.' }
\end{aligned}
$$

The above shows that [V- (regular) resultative particle] predicates behave like accomplishments whereas [ $\mathrm{V}-$ canl] predicates behave like achievements. This is further illustrated by the following contrast:

(35) Hoi1-zo2 gam3 do1 coeng1, zung1jyu1 dou1 se6-can1 keoi5 laa3. shoot-PERF so many gun, finally all shoot-CAN 3SG SFP 'After firing so many shots, finally a shot hit the target and hurt her/him to an unspecified extent.'

(36) Hoi1-zo2 gam3 do1 coeng1, zung1jyu1 dou1 se6-sei2 keoi5 laa3. shoot-PERF so many gun, finally all shoot-dead 3SG SFP

Reading 1: 'After firing so many shots, finally a shot hit the target and killed her/him.'

Reading 2: 'After firing so many shots that hit the target, s/he was finally killed.'

In (36) with se6-sei2 'shoot-dead', the sentence is compatible with a durative reading, which allows a time span for the progression of injury (accumulating after every shot) till the end point of "death" (reading 2). (35) is incompatible with such reading. There cannot be any time span between getting shot and reaching the harm level of canl.

10 Hai2dou6 literally means 'at here', but it is also used to mean 'right now'. 
According to $\mathrm{Gu}$ and Yip (2004), even though $\mathrm{V}$ and canl encode the aspectual meaning of process/activity and outcome/result, respectively, these aspectual components cannot be viewed by the speaker independently of each other because [V-canl] predicates are conflated forms. The process/activity component is thus inaccessible to the speaker, which explains why [V-can 1] predicates behave like achievements. ${ }^{11}$

I believe the obligatory achievement reading is related to the non-specific value of can 1. Beaver (2013) proposes that there are two types of scales: simplex and complex. Simplex scales have only two sub-parts, the starting point and the end point; complex scales have more than two sub-parts, minimally the starting point, the middle, and the end point. The two kinds of scales combine with different affectedness types to give rise to different kinds of aspectual classes as presented in the table below:

\begin{tabular}{|c|c|c|}
\hline Verbs & Simplex scale & Complex scale \\
\hline Quantized & $\frac{\text { Achievements }}{(\text { break a vase, kill Bill) }}$ & $\begin{array}{l}\text { Accomplishments } \\
\text { (load the wagon, eat the apple) }\end{array}$ \\
\hline Non-quantized & N/A & $\begin{array}{l}\text { Degree Achievements } \\
\text { (cool the soup) }\end{array}$ \\
\hline Potential & Semelfactives (hit, slap) & Activities (beat, pummel) \\
\hline Unspecified & $\underline{\text { Semelfactives }(\text { blink) }}$ & Activities (rub the lamp) \\
\hline
\end{tabular}

A quantized change indicates a transition from one state to another. When canl is added to a non-quantized and potential predicate, the predicate becomes quantized:

(38) Non-quantized V/potential V + canl: $\exists \mathrm{e} \exists \mathrm{s} \exists \mathrm{g}$ [result' $\left.\left(\mathrm{x}, \mathrm{s}, \mathrm{g}_{\text {canl }}, \mathrm{e}\right)\right]$

$\mathrm{X}$ is a theme along a scale $\mathrm{s}$ in event e. In [V-canl] predicates, canl supplies a certain goal state on $\mathrm{s}, \mathrm{g}_{\text {canl }}$. Canl can be any point along the "bodily harm" property scale. Since canl can be any value at all (even the smallest degree can be considered canl), it cannot have any middle portion. So, it will always be a simple binary transition, a simplex scale. The resultant aspectual type is thus always achievements.

\subsection{Syntactic analysis}

Let's recapitulate what has been discussed so far before moving on to the syntactic treatment of canl. Can1 is a post-verbal resultative particle and is in

11 One reviewer pointed out that it is possible to add gwai2 'ghost', an intensifier, between the verb and can1, as in [V-gwai2-can1]. It is generally possible to put gwai2 between the verb and postverbal particles (e.g., aspectual particles and resultative particles, see Lee and Chin 2007 for discussion). This suggests that [V-canl] predicates do not behave differently in terms of insertion possibility from other [V-post-verbal particle] predicates and [V-canl] predicates might not be conflated forms. 
complementary distribution with other resultative particles. However, it is different from regular resultative particles (e.g., sei2 'dead', soengl 'injured') in two ways: (a) canl does not have lexical content and so cannot be used as a regular predicate; (b) [V-canl] predicates behave like achievements while [V-(regular) resultative particle] predicates behave like accomplishments. Regarding (b), I argued that the achievement nature of [V-canl] predicates is related to the "any value" property of canl. Since any degree of "bodily harm" can be interpreted as the end point, there can never be any middle portion. So, [V-canl] predicates function like a simplex scale (a two-point scale).

The semantic opacity and the obligatory achievement reading liken can 1 to another kind of post-verbal particles: phase complements (Chao 1968: 446), which I have briefly mentioned earlier on. Phase complements are elements that are semantically bleached. They indicate that the action denoted by the verb has a definitive end point. Consider the Cantonese example below:

$\begin{array}{lll}\text { Pit1taa4 } & \text { gin3-dou2 } & \text { keoi5. } \\ \begin{array}{ll}\text { Peter } & \text { see-arrived/succ } \\ \text { 'Peter saw her/him.' }\end{array} & \text { 3SG }\end{array}$

In (39), dou2 is a phase complement. Literally it means 'arrived', but this meaning is not available in (39). Dou2 in gin3-dou2 in (39) has a bleached, non-lexical meaning. It means the "seeing" action has been achieved or as Lu et al. (2019) call it "brought to a successful end" (represented as succ in the gloss in (39) [Lu et al. 2019]). Interestingly, Lu et al. (2019) observe that [V-phase complement] predicates behave like achievements, unlike [V- (regular) resultative particle] predicates. Their data are from (two Chinese dialects) Mandarin and Xiang, but the same pattern can also be observed in Cantonese. [V-phase complement (e.g., dou2)] predicates are not compatible with the progressive aspectual particle gan2, while [V-resultative particle (e.g., sei2 (dead)] predicates are:

\begin{tabular}{|c|c|c|}
\hline *Pit1 taa4 & se6-dou2-gan2 & zek3 \\
\hline Peter & shoot-arrived/ ${ }_{\text {SUCC }}$-PROG & $\mathrm{CL}$ \\
\hline
\end{tabular}

$\begin{array}{llll}\text { Pit1taa4 se6-sei2 -gan2 } & \text { zek3 } & \text { gwaai3sau3. } \\ \text { Peter shoot-dead/ succ -PROG } & \text { CL } & \text { monster } \\ \text { 'Peter is in the process of shooting the monster to death.' }\end{array}$

Lu et al. (2019) call phase complements scale-reducers: they reduce a multi-point scale to a two-point scale. Lu et al. (2019) provide an analysis in which achievements and accomplishments are accounted for in structural terms. According to them (see also Sybesma 2017), there are 3 aspectual projections between $v$ (Voice)P and VP, which are relevant for the encoding of inner aspect/situation aspect:

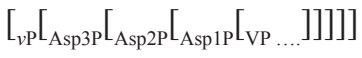

Asp1P is related to telicity. It provides an endpoint to the event encoded by $\mathrm{V}$. Result-denoting elements, which are fully lexical predicative elements (e.g., qióng 
'poor'), are located in $\mathrm{Aspl}^{0}$. Asp3P is related to realization. It encodes whether the endpoint is realized or not. For example, the perfective aspectual particle le in Mandarin is in $\mathrm{Asp}^{0}$. Phase complements are in $\mathrm{Asp}^{\circ}$.

Canl is similar to phase complements and differs from regular resultative particles in two ways: (a) canl lacks lexical meaning; (b) [V-canl] predicates are achievements rather than accomplishments. However, different from phase complements, which do not seem to be predicative of any argument, canl does (at least with our analysis that canl is related to bodily harm). Based on this, I will place can 1 in Asp2 ${ }^{0}$ and the affected argument in SpecAsp2P. (43) (transitive) and (44) (intransitive) would have the structures of (45) and (46) respectively (the structure on top of $v \mathrm{P}$ is not given):
Pit1taal zong6-can1
zek3 maau1 aa3.
Peter bump.into-CAN CL cat SFP

'Peter bumped into the cat and as a result the cat was hurt.'
Zek3 maau1 zong6-can1
aa3.
CL cat bump.into-CAN SFP

'There was a bumping event and as a result the cat was hurt.'

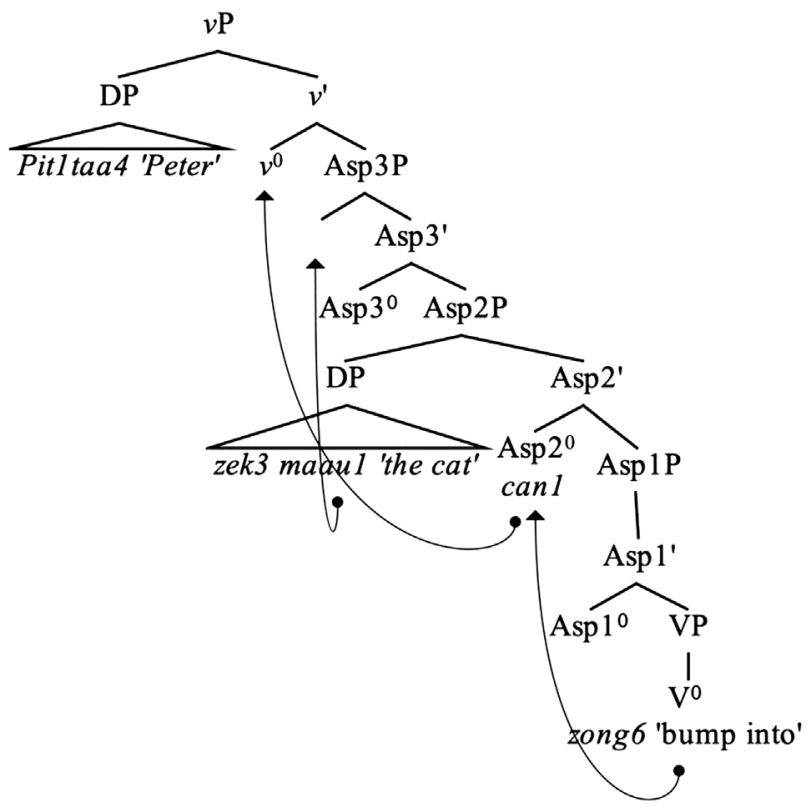

In the transitive cases, the affected object is generated in SpecAsp2P and canl is in Asp2 $2^{0}$. The verb zong6 moves up Asp2 ${ }^{\circ}$ to pick up can 1 and then together move to $\mathrm{v}^{0}$. The affected argument zek3 maaul moves to SpecAsp3P for case licensing and the external argument Pitltaa 4 will move to SpecTP for case licensing (which is not presented here). 
(46)

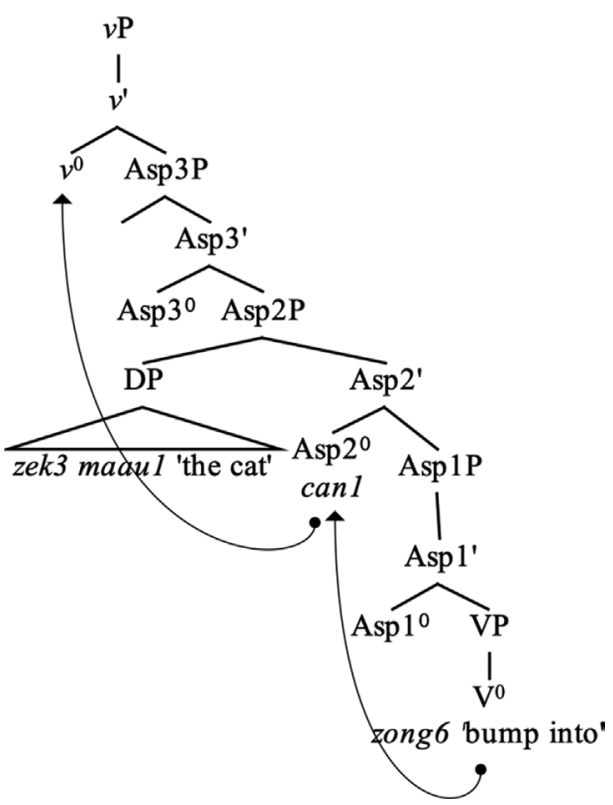

(46) is similar to (45) except that there is no external argument. The affected argument moves to SpecTP for case licensing.

Since can 1 is in complementary distribution with other resultative particles, Asp $2^{0}$ and $A s p 1^{0}$ are never filled at the same time. However, can 1 is compatible with aspectual particles, e.g., gwo3 (experiential), zo2 (perfective), which occupies $\mathrm{Asp}^{0}$. In such cases, can 1 moves to $\mathrm{v}^{0}$ along Asp3 ${ }^{0}$, picking up the aspectual particle on the way. ${ }^{12}$

\section{Habitual can1}

In this section, I provide a brief discussion on the syntactic and semantic properties of the habitual canl. The habitual canl does not seem to pose any selectional restrictions on the verb it combines with, except that it is not compatible with verbs that denote a permanent property (e.g., hai6, the verb to be as in "whenever he is a student...") or events that could only happen once (e.g., sei2 'die', as in "whenever he dies...") (Tang 2015). ${ }^{13}$ Unlike the adversative canl, it is not restricted to verbs

12 There might be a problem with putting can 2 in Asp $2^{0}$. Different from can1, phase complements scope over the whole predicate/event. However, since canl also cannot be in Asp3 ${ }^{\circ}$ (canl can co-occur with aspectual particles indicating realization such as zo2) or $\mathrm{Aspl}^{0}$ (unlike other resultative particles, canl has no lexical content, and cannot function as a predicate in other contexts), we have tentatively put can1 in Asp2 ${ }^{0}$. It might be the case that more projections are needed between $v \mathrm{P}$ and VP.

13 Phonologically, unlike the adversative canl, the habitual canl can more naturally combine with disyllabic verbs to its left, e.g., faanljik6-canl 'whenever translating..., gaai2sik1-can1 'whenever explaining...'. 
associated with bodily harm (with non-quantized or potential affectedness). It does not require an affected sentient argument. Moreover, it is compatible with both stative (e.g., tai2 'see') and dynamic verbs (e.g., paau2bou6 'run').

(47) Ngo5 tai2-can1 hei3 dou1 fan3-zoek6 gaa3. 1SG see-CAN movie all sleep-fallen SFP

'I fall asleep whenever I see a movie.'

$\begin{array}{lllll}\text { Ngo5 paau2-can1-bou6 } & \text { dou1 } & \text { au2 } & \text { gaa3. } \\ \text { 1SG run-CAN-step } & \text { all } & \text { vomit } & \text { SFP } \\ \text { 'I vomit whenever I run.' } & & & \end{array}$

Even though the habitual canl does not seem to pose any selectional restrictions on the verb, it is subject to other distributive restrictions. The habitual canl cannot appear in episodic sentences and is not compatible with aspectual particles (unlike the adversative can1). ${ }^{14}$ The distribution of the habitual canl is further restricted in non-episodic environments. It can only appear in the protasis of what Cheng and Huang (1996) call "dou-conditionals" (which looks like a free relative [FR]), or in conditional sentences with zau6 'then', which is considered a conditional marker (Cheng and Huang 1996).

$\begin{array}{lllll}\text { Ngo5 } & \text { sik6-can1 mong1gwo2 dou1 tou5-tung3 } & \text { gaa3. } \\ \text { 1SG eat-CAN mango } & \text { all } & \text { stomach-hurt } & \text { SFP } \\ \text { 'Whenever I eat mango, my stomach hurts.' } & \end{array}$
(50) Ngo5 sik6-can1 mong1gwo2 zau6 tou5-tung3 gaa3 laa3. 1SG eat-CAN mango then stomach-hurt SFP SFP 'In any event that I eat mongo, my stomach hurts.'

(51) Juk1-can1 dou1 daa2. move-CAN all beat 'If you move in any way, I will beat you.'

(52) Juk1-can1 zau6 daa2. move-CAN then beat 'If you move, I will beat you.'

Based on the non-episodic restriction and universal-like reading, I propose an analysis which treats the habitual canl as a Free Choice Item (FCI). Following Giannakidou and Cheng (2006) and Cheng and Giannakidou (2013), I assume that the habitual canl cannot appear in episodic sentences as it contains a dependent world variable (w) that cannot be free but must be bound by some $\mathrm{Q}$ (uantificational)-operator, thus restricting its appearance in the presence of doul (iota operator) or conditionals with zau6 'then' (necessity operator).

14 A sentence is episodic when it is about exactly one event that happens at a particular time (Giannakidou 2001). 
Giannakidou and Cheng (2006) distinguish two kinds of nominal FCIs in Mandarin Chinese, namely, definite and indefinite. The following examples are taken from Cheng and Giannakidou (2013):

(53) rúguǒ (yǒu) nă-ge rén dă-diànhuà lái jìu shuō wǒ bú zài if have which-CL person telephone come, then say I not be 'If anyone calls, say that I'm not here.'

(54) (wúlùn) nă-ge rén dă-diànhuà lái, wǒ dōu bú zài no-matter which-CL person telephone come I all not be 'Whoever calls, I'm not here.'

In the scenario in which the phone is ringing, only (54) is acceptable. Giannakidou and Cheng (2006) argue that dou contributes to the tendency observed in definite plurals and FR, which is to exclude the empty set. In the presence of dou in (54), the FCI is definite (similar to wh-ever) and in the absence of dou in (53), the FCI is indefinite (similar to any). Only the douconditional is compatible with the existence of phone calls and can be used when the phone is ringing.

A similar contrast can be observed with the habitual canl, but in the cases below, the FCI can 1 applies to events. There are no individual variables but instead, there are event variables. Consider the following scenario. There is a phone which has number recognition feature. The phone rings and you see that John is calling. But Peter just does not pick up the phone. And in fact, you notice that every time John calls, Peter does not pick up the phone. Peter explains the situation to you. In such a scenario, only the $d o u$-conditional is appropriate:
Aa3-John
daa2-can1
din6waa2
lei4 ngo5
zau6
m4 zip3. ${ }^{15}$
AA-John
call-CAN phone
come $1 \mathrm{SG}$
then NEG
pick.up
daa2-can1
din6waa2
lei4
ngo5
dou1 m4 zip3.
AA-John
call-CAN phone
come $1 \mathrm{SG}$
all
NEG pick.up

(56) Aa3-John

In the above scenario, it is more natural to utter (56), where doul is present. I suggest that the contrast between (55) and (56) is the contrast between indefinite $\mathrm{FCI}$ and definite FCI. In the presence of doul, the FCI is interpreted as definite and thus excludes an empty set (of events of John calling). (56) contains an expectation that John will call, and thus when John is calling, (56) feels more appropriate.

Dou1 is a maximality/iota operator. It applies maximality to a contextually determined plural set. In (56), the event variable is intensionalized by the application of the w variable and the intension of the event will be the input to doul, which will then give you the exhaustive list of events of John calling. In the case of (55), the

15 Aa3 is a prefix that attaches to [+human] familiar terms, see Sio and Tang (2020) for a detailed discussion. 
event variable is also intensionalized by the application of the w variable, but there is no maximality effect as doul is absent.

The maximality effect of doul can be shown with the use of caalm4do1 'almost':

Ngo5 caa1m4do1 sik6-can1 mong1gwo2 dou1 tou5-tung3 gaa3.
1SG almost $\quad$ eat-CAN mango
'It is almost the case that whenever I eat mangoes, my stomach hurts.'

$\begin{array}{lllllll}* \text { Ngo5 } & \text { caa1m4do1 } & \text { sik6-can1 } & \text { mong1gwo2 } & \text { zau6 } & \text { tou5-tung3 } & \text { gaa3. } \\ \text { 1SG } & \text { almost } & \text { eat-CAN } & \text { mango } & \text { then } & \text { stomach-hurt } & \text { SFP }\end{array}$

Intended reading: 'It is almost the case that every time I eat mangoes, my stomach hurts.'

For caalm4do1 'almost' to work, one needs to know the totality of mango-eating events. Only in the presence of doul, the reading is exhaustive and compatible caalm4dol 'almost'.

I would also like to point out that canl as an FCI does not only appear in the post-verbal position, but also appears in the preverbal position, where temporal adverbials are placed:

$\begin{array}{llllll}\text { Ngo5 fung4-can1 sik6 mong1gwo2 } & \text { dou1 tou5-tung3 } & \text { gaa3. } \\ \text { 1SG when-CAN eat mango } & \text { all } & \text { stomach-hurt } & \text { SFP } \\ \text { 'Whenever I engage in a mango-eating event, my stomach hurts.' }\end{array}$

(60) Ngo5 fung4-can1 sik6 mong1gwo2 zau6 tou5-tung3 gaa3 laa3. $1 \mathrm{SG}$ when-CAN eat mango then stomach-hurt SFP SFP

'Whenever I engage in a mango-eating event, my stomach hurts.'

(61) Ngo5 cam4jat6 sik6-zo2 mong1gwo2.

$1 \mathrm{SG}$ yesterday eat-PERF mango

'I ate mangoes yesterday.'

(61) shows the position of temporal adverbials in episodic sentences. In (59) and (60), canl appears with fung4, which means 'when' (non-interrogative). Similarly, (59) is compatible with caalm4dol 'almost' whereas (60) is not. There seems to be no difference in the meaning between having the canl in the adverbial position after fung4 and in a post-verbal position.

\section{Conclusion}

This paper discusses and analyzes the grammatical properties of the two functions of the post-verbal canl. The first function of the post-verbal canl is a non-specific resultative particle that denotes any degree on a "bodily harm" scale. This explains its verbal selection restriction as well as why [V-canl] predicates behave like achievement verbs. The second function of the post-verbal canl is a free choice item (FCI). This explains its restrictive appearance: it only appears in 
non-episodic sentences, specifically in doul (iota operator)-conditionals or zau6 (necessity operator)-conditionals.

\section{Acknowledgments}

I would like to thank the anonymous reviewers for their valuable comments and the editorial team for their help in the whole submission process. I am also grateful to Boban Arsenijevic, Lisa Cheng, František Kratochvíl, Rint Sybesma, and Sze-Wing Tang and especially the audience at the 1st International Workshop on Cantonese Syntax (held on June 27-28, 2019 at Palacký University in Olomouc, Czech Republic) for their feedback and discussion on the paper. The research described here is supported by the European Regional Development Fund - Project "Sinophone Borderlands - Interaction at the Edges" CZ.02.1.01/0 .0/0.0/16_019/0000791.

\section{References}

Beavers, John. 2011. On affectedness. Natural Language \& Linguistic Theory 29(2). $335-370$.

Beavers, John. 2013. Aspectual classes and scales of change. Linguistics 51(4). 681-706.

Chao, Yuan Ren. 1968. A grammar of spoken Chinese. Berkeley, CA: University of California Press.

Cheng, Lisa Lai-Shen. 2008. On every type of quantificational expression in Chinese. In Anastasia Giannakidou \& Monika Rathert (eds.), Quantification, definiteness and nominalization, 53-75. New York: Oxford University Press.

Cheng, Lisa Lai-Shen \& Anastasia Giannakidou. 2013. The non-uniformity of Whindeterminates with polarity and free choice in Chinese. In Kook-Hee Gil, Steve Harlow \& George Tsoulas (eds.), Strategies of quantification (Oxford Studies in Theoretical Linguistics), 123-154. Oxford: Oxford University Press.

Cheng, Lisa Lai-Shen \& C.-T. James Huang. 1996. Two types of Donkey Sentences. Natural Language Semantics 4. 121-163.

Cheung, Samuel Hung-Nin. 2007. Xianggang Yueyu yufa de yanjiu [A grammar of Cantonese as spoken in Hong Kong]. Hong Kong: The Chinese University of Hong Kong Press.

Giannakidou, Anastasia. 2001. The meaning of free choice. Linguistics and Philosophy 24. 659-735.

Giannakidou, Anastasia \& Lisa Lai-Shen Cheng. 2006. (In)definite, polarity, and the role of wh-morphology in free choice. Journal of Semantics 23. 135-183.

$\mathrm{Gu}$, Yang \& Virginia Yip. 2004. On the Cantonese resultative predicate V-can. Concentric: Studies in Linguistics 30. 35-67.

Hay, Jennifer, Christopher Kennedy \& Beth Levin. 1999. Scalar structure underlies telicity in "degree achievements". In Tanya Matthews \& Devon Strolovitch (eds.), Proceedings of the Semantics and Linguistic Theory (SALT) 9, 127-144. Ithaca, NY: CLC Publications. 
Kennedy, Christopher. 2001. Polar opposition and the ontology of 'degrees'. Linguistics and philosophy 24(1). 33-70.

Lee, Peppina Po-Lun. 2017. Quantification in Cantonese. In Denis Paperno \& Edward Keenan (eds.), Handbook of quantifiers in natural language: Volume II (Studies in Linguistics and Philosophy 97), 61-111. Cham: Springer International Publishing.

Lee, Peppina Po-Lun \& Andy Chi-On Chin. 2007. A preliminary study on Cantonese gwai 'ghost'. In Sze-Wing Tang \& Joanna Ut-Seong Sio (eds.), Studies in Cantonese linguistics 2, 33-54. Hong Kong: Linguistic Society of Hong Kong Publications.

Li, David C.S. 2000. Phonetic borrowing: Key to the vitality of written Cantonese in Hong Kong. Written Language \& Literacy 3(2). 199-233.

Lu, Man, Anikó Lipták \& Rint Sybesma. 2019. A structural account of the difference between achievements and accomplishments: Evidence from Changsha Xiang Chinese. Journal of East Asian Linguistics 28. 279-306.

Matthews, Stephen \& Virginia Yip. 2011 [1994]. Cantonese: A comprehensive grammar, 2nd edn. London \& New York: Routledge.

Sio, Joanna Ut-Seong. 2015. Scalarity and the Cantonese post-verbal particle can1. In Stefan Muller (ed.), Proceedings of the 22nd International Conference on HeadDriven Phrase Structure Grammar, Nanyang Technological University (NTU), Singapore, 234-241. Stanford, CA: CSLI Publications. http://web.stanford.edu/group/ cslipublications/cslipublications/HPSG/2015/sio.pdf (accessed 6 October 2020).

Sio, Joanna Ut-Seong \& Sze-Wing Tang. 2020. Two types of aa3-nominals in Cantonese. Language and Linguistics 21(1). 80-103.

Sybesma, Rint. 2017. Aspect, inner. In Rint Sybesma, Yueguo Gu, Zev Handel, C.-T. James Huang \& James Myers (eds.), Encyclopedia of Chinese language and linguistics, vol. 1, 186-193. Leiden: Brill.

Tang, Sze-Wing. 2015. Yueyu yufa jiangyi [Lectures on Cantonese grammar]. Hong Kong: The Commercial Press.

Tenny, Carol. 1994. Aspectual roles and the syntax-semantics interface. Dordrecht: Kluwer Academic.

Tortora, Christina. 1998. Verbs of inherently directed motion are compatible with resultative phrases. Linguistic Inquiry 29. 338-345.

Yue-Hashimoto, Anne. 1991. The Yue dialects. In William. S. Y. Wang (ed.), Languages and dialects of China (Journal of Chinese Linguistics Monograph 3), 237-293. Berkeley, CA: Project on Linguistic Analysis.

$\begin{array}{ll}\text { Mailing address: } & \begin{array}{l}\text { Joanna Ut-Seong Sio } \\ \text { Department of Asian Studies, Faculty of Arts, Palacký University } \\ \text { Olomouc, Kř́žkovského 14, } 779 \text { 00 Olomouc, Czech Republic. }\end{array} \\ \text { Email: } & \text { joannautseong.sio@upol.cz } \\ \text { Received: } & \text { January 20, 2020 } \\ \text { Accepted: } & \text { June 5, 2020 }\end{array}$




\title{
粵語中動詞後綴 “親”的雙重身分：不確指結果補語和自由 選項單元
}

\author{
蕭月嫦 \\ 帕拉茨基大學
}

\section{提要}

本文探討粵語中動詞後経 “親” 兩種不同的語法身分及其語法和語義屬性。 動詞後経 “親” 的其一身分是不確指結果補語 (non-specific resultative particle)。 “動詞一親” 含身體損傷比例尺。由於結果補語 “親” 可指任何程度的損傷，“動詞一 親” 內含的比例尺只能是單純形 (只包含開端和結束兩個點 ), 因此 “動詞一親” 有 成就性動詞的屬性。動詞後経 “親” 的另一身分是自由選項單元 (free-choice-item)。 自由選項單元 “親” 只能出現在非情節性 (non-episodic) 句子, 含 “都” (iota operator) 或含 “就” (necessity operator) 的條件句。

\section{關鍵詞}

粵語, 結果補語, 比例尺, 自由選項單元 